\title{
Female Sexual Dysfunction before and after Diagnosis of Infertility
}

\author{
Orji Ernest $\mathrm{O}^{1^{*}}$, Ogunjuyigbe Peter $\mathrm{O}^{2}$ \\ ${ }^{1}$ Department of Obstetrics and Gynaecology, Obafemi Awolowo University, Ile-Ife. Obafemi \\ Awolowo University Teaching Hospital Complex, Ile-Ife, Nigeria \\ ${ }^{2}$ Demography and Social Statistics, Obafemi Awolowo University, Ile-Ife, Nigeria
}

\begin{abstract}
This study determined the prevalence, domain, and predictors of sexual dysfunction among 222 infertile women before and after Diagnosis of infertility in Ife East Senatorial district, Nigeria. They were interviewed using interviewer-administered questionnaire and Female Sexual Function Index assessment tool. Information about their sexual functions after marriage and before the couple started having difficulty in getting pregnant were obtained and compared with sexual functions after Diagnosis of infertility. Data management was done using SPSS Version22 and STATA 12. The Chisquare test was used to test associations. P-value of was set $<0.05$. Before infertility diagnosis, the prevalence of sexual dysfunction was 23.9\%. After infertility diagnosis, this increased to $57.2 \%$, $P<0.001$. The mean scores of female sexual function index for infertile patients were $29.57 \pm 5.10$ before the infertility diagnosis but reduced to $24.42 \pm 5.86$ after infertility diagnosis $P<0.001$. The domain scores reduced after Diagnosis of infertility, and it shows statistical significance at $P<0.001$. Significant predictors at multivariate analysis include increasing maternal age, increasing duration of infertility, Hausa /Fulani tribe, and female genital mutilation. Infertility increases the prevalence of female sexual dysfunction and reduces the domain scores of sexual functions.
\end{abstract}

Keywords: Dysfunction, Female, Infertility, Sexual.

\section{Introduction}

Female sexual dysfunction (FSD) is defined as "disturbance in sexual desire and psychophysiological changes that characterize the sexual response cycle causing marked distress or interpersonal difficulty" [1]. The prevalence of FSD varies from $11 \%$ to $65 \%[2,3]$, depending on the population studied. It was initially believed that sexual dysfunction (SD) is a disease of developed countries due to their sexual freedom. However, emerging research in Nigerian populations had revealed that sexual dysfunction might also be a significant problem.

Most studies on sexual dysfunction were in developed countries with conflicting results $[4$, 5]. While some studies revealed that infertile women are more predisposed to developing sexual dysfunction $[6,7]$, others observed no such significant difference $[1,2,3,5]$. There is thus no consensus in this area. Published studies on sexual dysfunction among infertile women are very few in Africa and among Nordic women $[1,2,7]$. There is no study both in Nigeria and in Nordic countries on FSD before and after Diagnosis of infertility in the same population using the female sexual function index assessment tool. There is certainly the need for studies on this topic to fill the extant knowledge gaps. It is also important to evaluate sexual dysfunction in the African context since its predictors are multifaceted and may differ from region to region. Appropriate identification of predictive and protective factors would likely assist the gynecologists and others in identifying populations of infertile women at risk. Additionally, it will assist in 
revealing modifiable factors that will minimize this problem in the affected population. It may also help the gynecologist to evaluate patients and involve a psychiatrist or psychologist if necessary. To evaluate the impact of infertility on sexual dysfunction, most authors compared sexual functions between infertile and fertile women. There is a scarcity of studies comparing sexual functions among the same women before and during infertility. This type of study, the authors believe, will give a better picture of the impact of infertility on sexual functions. This study determined and compared the prevalence and domain of sexual dysfunction before and during infertility in Ife East Senatorial district, Nigeria. The study also determined the predictors of sexual dysfunction. This is the first study available in literature where sexual functions were assessed before and after an infertility diagnosis.

\section{Methods}

This study was conducted at the infertility clinics of the Department of Obstetrics and Gynaecology of the Obafemi Awolowo University Teaching Hospitals Complex Ile-Ife, Nigeria. Using a systematic sampling technique, 222 infertile women at the infertility clinic were recruited from 2020 to 2021.

The interviewer-administered questionnaire for patients consisted of socio-demographic characteristics and Female Sexual Function Index (FSFI) tool. Data were managed using SPSS Version 22 and Stata 12. Three levels of analysis were employed. The first level was the descriptive and univariate analysis to tabulate the statistics of respondents' characteristics. The second level involved bivariate analysis in determining the relationship between the dependent variable (female sexual dysfunction) and independent variables. The third level of analysis was the multivariate analysis which was done through the application of different mathematical models to know the influence of the predictor variables on the response variables. The Chi-square was used to test association, and the P-value was set at a level of $<0.05$.

This study was approved by the Ethics and Research Committee (ERC) of the OAUTHC Ile-Ife, Nigeria (Protocol No: ERC/2019/12/14) and by Health Research Ethics Committee, Institute of Public Health, Obafemi Awolowo University, Ile-Ife, Nigeria (Protocol No: IHUOAU/12/1389).

\section{Results}

Table 1 showed that before Diagnosis of infertility, the prevalence of SD was 53(23.9\%), but after the Diagnosis of infertility, this increased to $127(57.2 \%), \mathrm{P}<0.001$. Table 2 showed that mean scores of female sexual function index for infertile patients was 29.57 \pm 5.10 before the Diagnosis of infertility but reduced to $24.42 \pm 5.86$ after infertility diagnosis, which shows statistical significance at $<0.001$. The domain scores reduced after Diagnosis of infertility, and it shows statistical significance at $<0.001$.

Table 1. Comparing Prevalence of Female Sexual Dysfunction before and after Diagnosis of Infertility

\begin{tabular}{|l|l|l|l|l|}
\hline \multirow{2}{*}{ Infertility } & Have FSD & Do not have FSD & $\chi^{2}$ & P \\
\cline { 2 - 4 } & $\mathbf{n}(\boldsymbol{\%})$ & $\mathbf{n}(\boldsymbol{\%})$ & 51.165 & \multirow{2}{*}{$\mathrm{p}<0.001$} \\
\hline Before Diagnosis of infertility & $53(23.9)$ & $169(76.1)$ & & \\
\hline Four weeks after diagnosis & $127(57.2)$ & $95(42.8)$ & & \\
\hline
\end{tabular}


Table 2. Comparing Overall and Domains Scores for Sexual Dysfunction before and after Diagnosis of Infertility

\begin{tabular}{|l|l|l|l|l|}
\hline \multirow{2}{*}{ Domains assessed } & Before infertility Diagnosis & After infertility Diagnosis & T & P \\
\cline { 2 - 5 } & Mean \pm SD & Mean \pm SD & & \\
\hline Overall mean & $29.57 \pm 5.10$ & $24.42 \pm 5.86$ & 9.653 & $<0.001$ \\
\hline Desire & $4.34 \pm 1.28$ & $3.57 \pm 1.04$ & 8.329 & $<0.001$ \\
\hline Arousal & $4.64 \pm 1.12$ & $3.77 \pm 0.95$ & 8.735 & $<0.001$ \\
\hline Lubrication & $5.17 \pm 0.90$ & $4.34 \pm 1.17$ & 9.535 & $<0.001$ \\
\hline Orgasm & $5.01 \pm 1.07$ & $4.05 \pm 1.25$ & 9.548 & $<0.001$ \\
\hline Satisfaction & $5.39 \pm 0.98$ & $4.51 \pm 1.40$ & 8.263 & $<0.001$ \\
\hline Pain & $5.02 \pm 1.25$ & $4.18 \pm 1.50$ & 7.994 & $<0.001$ \\
\hline
\end{tabular}

Table 3 showed that sexual dysfunction increases from $40 \%$ among those aged 20-29 years to $43.6 \%$ among those aged 30-39years and to $84 \%$ among those aged 40 years and above with a statistical difference of $\mathrm{P}<0.001$. Most of the women from the Hausa tribe (90.1\%) showed sexual dysfunction (P.022). There is no difference in religion, education, occupation, marital status, type of marriage, position in marriage. Other variables which showed significance at bivariate analysis apart from age at last birthday $(\mathrm{P}<0.001)$, duration of infertility $(\mathrm{P}<0.0001)$ and tribe $(\mathrm{P}<0.022)$ include husband income $(\mathrm{P}<0.002)$, multiple sexual partners $(\mathrm{P}<0.020)$, induced abortion
( $\mathrm{P}<0.041)$, hypertension $(\mathrm{P}<0.001)$, threat of separation $(\mathrm{P}<0.001)$, alcohol ingestion by husband $(\mathrm{P}<0.002)$, evidence of stress $(\mathrm{P}<0.001)$, pelvic pain $(\mathrm{P}<0.001)$, abdominal mass $(\mathrm{P}<0.010)$, poor perineal hygiene $(\mathrm{P}<0.009)$, female genital mutilation $(\mathrm{P}<0.001)$, narrowing of intriotus $(\mathrm{P}<0.001)$. Table 4 showed that logistic regression at multivariate analysis. Age last birthday $(\mathrm{P}<0.001)$, Hausa tribe $(\mathrm{P}<0.032)$, duration of infertility $(\mathrm{P}<0.007)$, any evidence of female genital mutilation $(\mathrm{P}<0.002)$, type 2 female genital mutilation $(\mathrm{P}<0.015)$ retained statistical significance. 


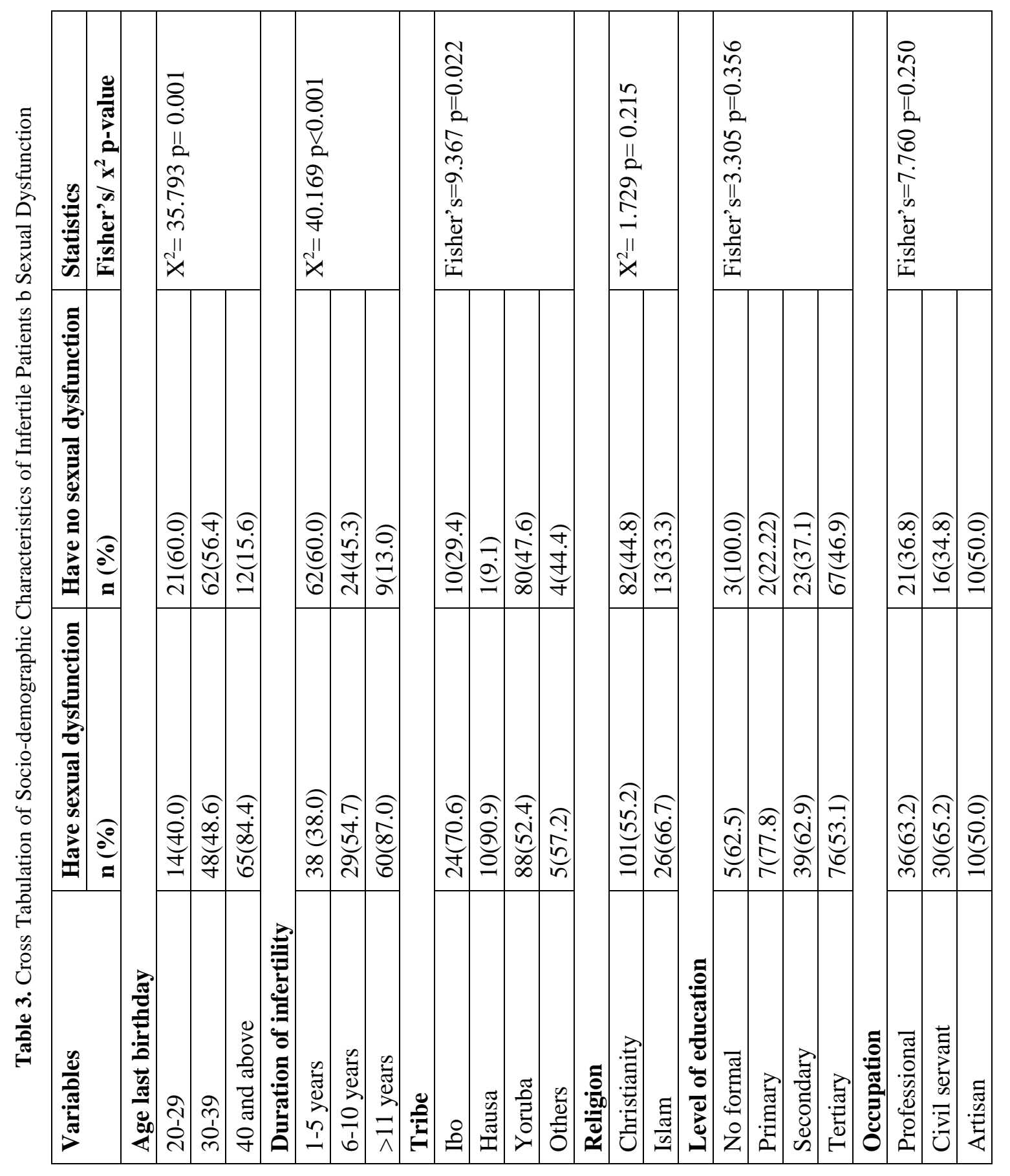




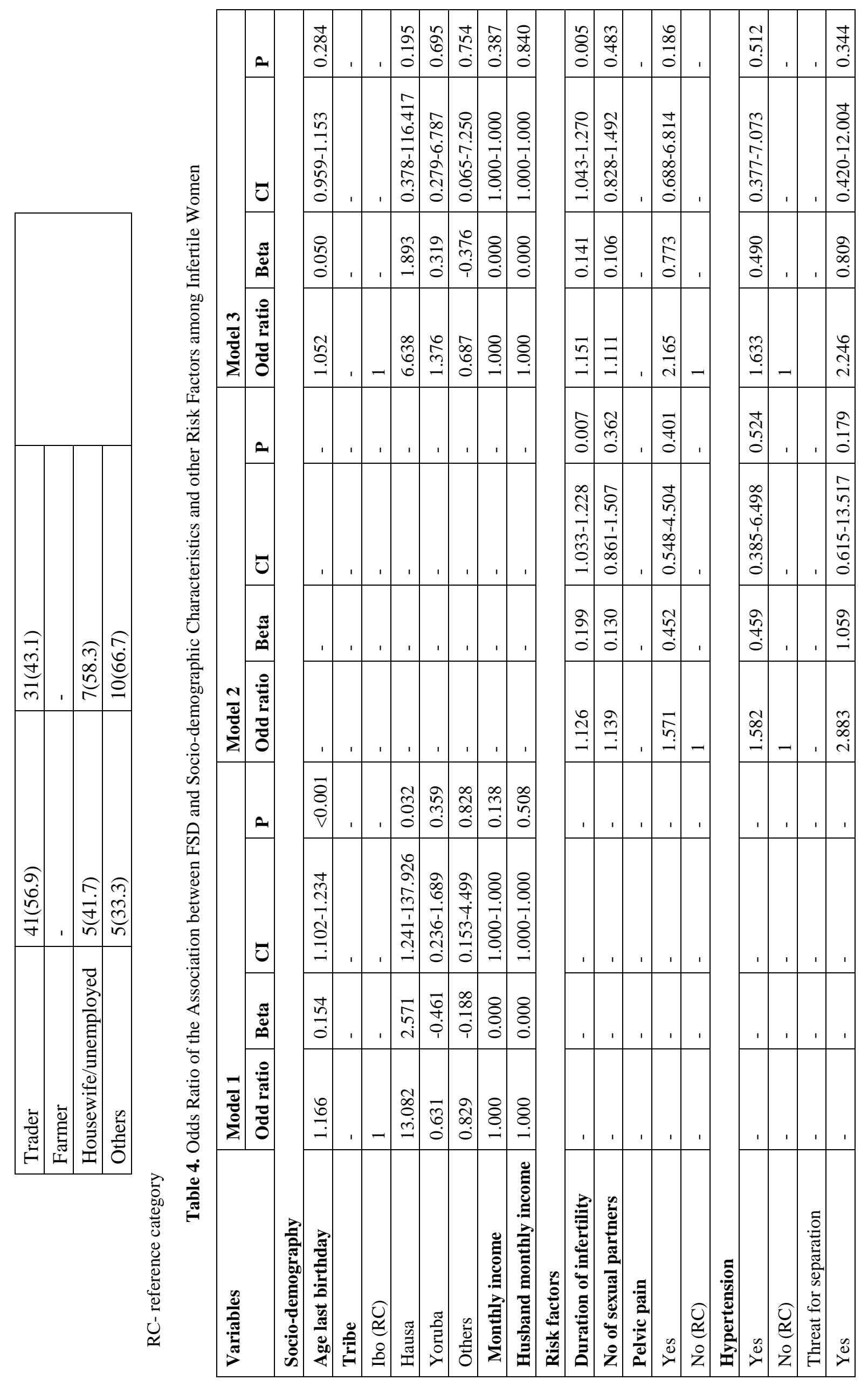




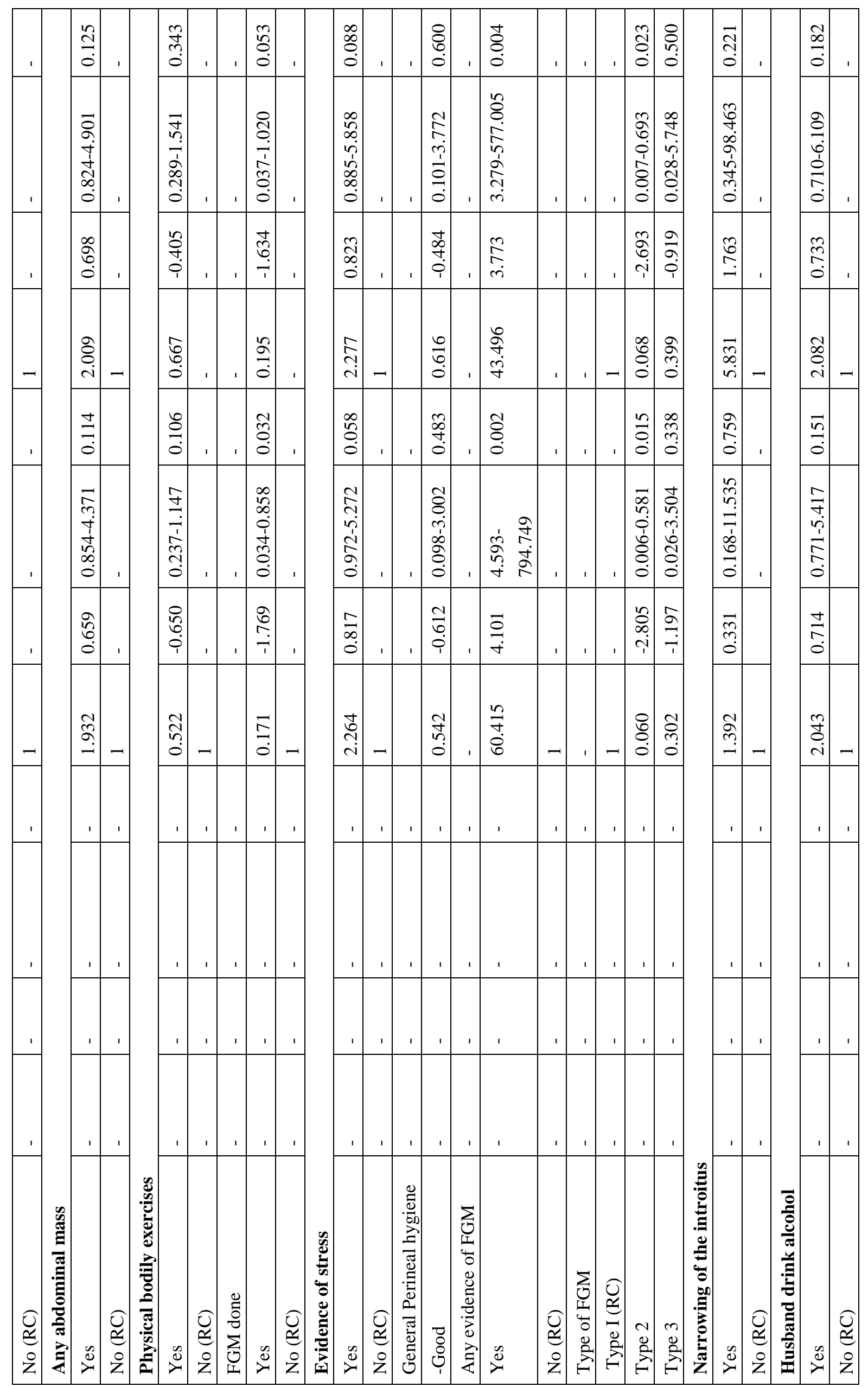




\section{Discussion}

The prevalence of FSD was $23.9 \%$ before Diagnosis but increased to $57.2 \%$ after Diagnosis of infertility was made. This, therefore, support the findings by some authors that sexual dysfunction are commoner among infertile women. Unfortunately, there are scarcities of similar studies in the literature to compare if truly sexual dysfunction is more in the same study group after Diagnosis of infertility. The prevalence of $57.2 \%$ among infertile women in our study is higher than $40 \%$ reported among infertile women in a United States of America study [6] 47\% reported among infertile women in Cairo, Egypt [8], $48 \%$ reported among infertile Iranian women [9]. This is a pointer to the fact that sexual dysfunction among infertile women is a significant problem necessitating a deliberate effort to explore its presence when evaluating infertile Nigerian women.

The mean FSFI scores decreased from 29.57 \pm 5.10 before the diagnosis to $24.42 \pm 5.86$ $(\mathrm{p}<0.001)$ after the infertility diagnosis. There was also a significant reduction in the mean domain scores of desires, arousal, lubrication, orgasm, satisfaction, and pain after Diagnosis of sexual dysfunction $(\mathrm{P}<0.001)$. The reason for lower mean scores after infertility diagnosis is that sexual activity is usually a spontaneous erotic adventure meant to cement marriage, boost self-image, and procreation in African settings. However, if for any reason there is some difficulty with procreation, sexual activity loses its spontaneity and erotic value because the main aim will become for conception. The resultant effect is sexual dysfunction.

The predictors of female sexual dysfunction at bivariate analysis include age at last birthday $(\mathrm{P}<0.001$.$) , Hausa tribe (\mathrm{P}<0.022)$ husband income $(\mathrm{P}<0.002)$, multiple sexual partners $(\mathrm{P}<0.001)$, the threat of separation $(\mathrm{P}<0.001)$, alcohol intake by husband $(\mathrm{P}<0.01)$ pelvic pain $(\mathrm{P}<0.001)$, poor perineal hygiene $(\mathrm{P}<0.009)$, evidence of female genital mutilation $(\mathrm{P}<0.001)$, type 2 female genital mutilation
$(\mathrm{P}<0.001)$ However at multivariate analysis only age at last birthday $(\mathrm{P}<0.001)$, Hausa tribe $(\mathrm{P}=0.032)$, duration of infertility $(\mathrm{P}=0.005)$, evidence of female genital mutilation $(\mathrm{P}=002)$, type 2 female genital mutilation $(\mathrm{P}=0.015)$ retained statistical significance. Increasing age at last birthday is 1.2 times more at risk, Hausa tribe has 13 times risk, increasing duration of infertility is 1.2 times at risk. Any evidence of Female Genital Mutilation increases the risk by 60 times.

Age at last birthday showed statistical significance at $\mathrm{P}<0.001$. The higher the age of infertile women, the higher the risk, especially at age 40 and above. Many factors combine to make increasing age a significant predictor variable. Sexual activity decreases after the age of 40 years [10]. There is a decline in the level of hormones especially estrogen level, which leads to varying degrees of vaginal atrophy [11]. There are also lower expectations with regard to sex or the perceived importance of sex in women as age increases [12]. While some studies found higher rates of SD in younger women [13], other studies suggested SD is higher in women, especially during the menopause transition [14]. It was reported that although sexual difficulties and SD increase with age, sexual dysfunction was actually more common in younger women [15].

The tribe was another predictor variable observed to show significant association with FSD $(\mathrm{P}=0.022)$. Women of the Hausa tribe had 10times risk for SD than women from other tribes such as Yoruba and Ibo. Generally, women in the Hausa tribe of northern Nigeria have no control of their sexual life. The men determine when to have sex or not with their wives and, as such do not recognize the emotional intimacy of women. Since a large component of sexual desire in women is a response rather than spontaneous, there is a likelihood of having FSD in such a population. A study among family planning users in the predominantly Hausa population of Kano State, 
Northern Nigeria, showed a high prevalence of FSD (87.7\%) [16].

Evidence of female genital mutilation (FGM) especially type 2, is associated with increased incidence of FSD $(83.9 \%$ versus $16.1 \% ; \mathrm{P}<0,001)$. The removal of sensitive parts of the vulva during circumcision reduces the sexual stimulation and desire in women. The resultant vulvar scarring makes it difficult for the penis to penetrate, leading to sexual difficulties with anorgasmia. It had been aptly observed that the origin and practice of FGM is shrouded in secrecy, uncertainty, and confusion $[17,18]$. FGM is done for archaic reasons, such as a tribal traditional practice that must be preserved and protected, a superstitious belief practised to preserve chastity and sexual purification. The campaign raised about the adverse consequences that had led to some gains by making many men and women support its abolition [19].

\section{Conclusion}

In conclusion, the prevalence of FSD increased after Diagnosis of infertility. The

\section{References}

[1] Oberg, K., Fugl-Meyer, A. and Fugl-Meyer, K., 2004. On categorization and quantification of women's sexual dysfunctions: An epidemiological approach. Int $J$ Impot Res 16, 261-269 https://doi.org/10.1038/sj.ijir.3901151.

[2] Ljungman, L., Lampic, C., Wettergren, L., et al., 2020. Sexual Dysfunction Among Young Adults in Sweden-A Population-Based Observational Study. Sex Med; 8:631-642.

[3] Valadares, A, L., Pinto-Neto, A.M., Osis, M.J., et al., 2008 Prevalence of sexual dysfunction and its associated factors in women aged 40-65 years with 11years or more of formal education: a populationbased household survey. Clinics (Sao Paulo); 63(6): 775-782.

[4] Alirezaei, S., Ozgoli, G., Alavi- Majd, H..2018 Evaluation of Factors Associated with Sexual mean scores of FSFI and domain scores also reduced after Diagnosis of infertility. The significant predictors include increasing maternal age, increased duration of infertility, being of Hausa /Fulani tribe, and having had FGM.

\section{Acknowledgments}

The authors thank the management of OAU, Ile-Ife, and the Needs Assessment Tet Fund, grant of the Federal Republic of Nigeria for the Scholarship of the Ph.D. research work from which this article was extracted. We thank Ms. Anjuna C, my Student Mentor, for her continuous encouragement, corrections, and instructions during this entire research work. I also appreciate my co-guide, Professor Ogunjuyigbe, for his untiring encouragement. I also appreciate the respondents interviewed in this study and my colleagues for granting me assess to use their patients.

\section{Conflict of Interest}

The authors declare no conflict of interest.

Function in Infertile Women. International Journal of Fertility and Sterility.; J12(2):125-129.

[5] deMendonça, C.R., MatiasNo, J.T., Campol, P.M., do Amaral, W.N.,.2017 Sexual dysfunction in infertile women: A systematic review and metaanalysis European Journal of Obstetrics Gynecology and Reproductive Biology 215(8):153-163.

[6] Millheiser, L.S., Helmer, A.E., Westphal, LM.; Millki, A.A., Lathii, R.B., 2010. Is an infertility risk factor for female sexual dysfunction? A case-control study. Fertility Sterility;94(6):2022-20025.

[7] Traeen, B., Stigum, H.,2010. Sexual problems in 18-67-year-old Norwegians. Scand J Public Health; 38:445-456.

[8] Gabr, A. A., Omran, E. F., Abdallah, A.A., Kotb, M. M., Farid, E.Z., Dieb, A. S., Belal, D. S.,2017. Prevalence of Sexual Dysfunction in Infertile versus Fertile Couples. European Journal of Obstetrics and Gynecology and Reproductive Biology; 2008.025. 
[9] Vahid, R. F., Ayati, S., Mirzaeian, S., Shakeri, M.T., Akhtardel, H.,2009. Fertility Outcome After IVF And Related Factors. Journal of Gorgan University of Medical Sciences 11, 3 (31): 42 To 46.

[10] Latif, E.Z. Diamond, M.P., 2013. Arriving at the Diagnosis of female sexual dysfunction. Fertile Sterile; Oct;100(4):898-904.

[11] Fajewonyomi, B. A., Orji, E. O., \& Adeyemo, A. O., 2007. Sexual dysfunction among female patients of reproductive age in a hospital setting in Nigeria. Journal of Health, Population, And Nutrition 25(1), 101.

[12] Hayes, R., Dennerstein, L, M., 2005.The Impact of Aging on Sexual Function and Sexual Dysfunction in Women: A Review of PopulationBased Studies. Journal Sexual Medicine;5(3):31730 .

[13] Mitchell, K.R., Mercer, C.H., Ploubidis, G.B., et al., 2013. Sexual function in Britain: Findings from the third National Survey of Sexual Attitudes and Lifestyles (Natsal-3). Lancet; 382:1817-1829. [14] Winkelman, W.D., Katz, P.P., Smith, J.F., Rowen, T.S., 2016. The Sexual impact of infertility among women seeking fertility care. Sex Med 4:190 197.
[15] Davari-TanhaM F., Mohseni, M., Gharjarzadeh, M., 2014. Sexual function in women with primary and secondary infertility in comparison with controls International Journal of Impotence Research; 26(4):132-4.

[16]Hendrick, L., Gijs, L., Enzlin, P., 2015.Agerelated prevalence rates of sexual difficulties, sexual dysfunctions, and sexual distress in heterosexual women: Results from an online survey in Flanders. J Sex Med; 12:424-435.

[17] Abdullahi, H.M., Abdurrahman, A., Ahmed, Z.D., Tukur, J., 2019. Female sexual dysfunction among women attending the family planning clinic at Aminu Kano Teaching Hospital: A cross-sectional survey. Niger J Basic Clin Sci; 16:32-7.

[18] Okeke, T.C., Anyaehie, U.S.B., Ezenyeaku, C.C.K., 2012. An overview of female genital mutilation in Nigeria Annals of Medical Health Sciences Research; 2(1):70-73.

[19]Leye, E., Eekert, N., V,, Shamu, S., Esho, T., Barrett, H., and ANSER., 2019.Debating medicalization of Female Genital Mutilation/Cutting (FGM/C): learning from (policy)experiences across countries Reproductive Health;16:158 https://doi.org/10.1186/s12978-019-0817-3. 